
legitimacy

\author{
Karolina Urbanska \\ Laboratoire de la Psychologie Sociale et Cognitive \\ Université Clermont Auvergne, France \\ karolina.urbanska@uca.fr
}

\title{
Samuel Pehrson
}

School of Psychology and Neuroscience

University of St Andrews, Scotland

sdp21@st-andrews.ac.uk

\begin{abstract}
***In press***
Urbanska, K. \& Pehrson, S. (in press). Using political sanctions to discourage intergroup attacks: Social identity and authority legitimacy. Behavioural and Brain Sciences. ${ }^{1}$
\end{abstract}

\author{
Word counts \\ Abstract: 58 \\ Main text: 976 \\ References: 303 \\ Entire text: 1337
}

\footnotetext{
${ }^{1}$ This article is a commentary on De Dreu, C.K.W. \& Gross, J. (2018). Revisiting the Form and Function of Conflict: Neurobiological, Psychological and Cultural Mechanisms for Attack and Defense Within and Between Groups. Behavioural and Brain Sciences. https://doi.org/10.1017/S0140525X18002170
} 
Using political sanctions to discourage intergroup attacks: Social identity and authority legitimacy

\begin{abstract}
De Dreu and Gross offer novel solutions to discouraging attackers via political sanctions. We offer insights from social psychological and criminological research on when such sanctions would work and when they could backfire. We argue that the influence of such sanctioning ultimately rests upon the extent to which such authorities can claim to represent the society they serve.
\end{abstract}

Authorities have a distinct position in our societies in that a mere appointment to such duty warrants a form of power and influence over society's behaviours. People usually obey authorities if they perceive them as legitimate (Tyler, 2006) and policies and reforms introduced by political authorities have a direct influence on social norms (Guimond et al., 2013; Tankard \& Paluck, 2016). In their article, De Dreu and Gross suggest that authorities are among solutions to prevent grave intergroup conflict by introducing political sanctions, discouraging potential attackers. In this commentary, we elaborate on this argument by considering when political sanctioning can be effective in preventing conflict and when it could backfire, provoking reactive attacks further. We argue that the extent to which authority is perceived to represent people they are meant to serve is key in the extent to which political sanctions are effective.

On one level, the effect of political sanctioning on behaviour seems straightforward: sanctions discourage behaviours by altering the cost-benefit considerations such that unwanted behaviours become more costly to the actor. From this point of view, it does not matter what kind of relationship exists between the authority and potential attacker so long the latter is afraid of losing resources valuable to their group should they disobey the former. These ideas go back to the early theories on equity (Adams, 1966; Messick \& Cook, 1983), whereby people are considered to be rationally weigh potential gains to one's own investments in an exchange. Judgements of authority resource distributions, in this perspective, are underpinned by the crude input-output exchanges. As De Dreu and Gross acknowledge, attacks tend to be less coordinated and, in turn, riskier; having another danger relating to the subsequent sanction could indeed decrease the likelihood of an attack. Thus, if instrumental motives were the sole basis for complying with authorities then people would comply when the promise of rewards and threat of sanctions are such that compliance maximises benefits (or minimises loss).

But are authorities simply sources of rewards and punishments? Tyler and colleagues have long argued that people obey authorities that treat them fairly for relational rather than instrumental reasons; such fair and respectful treatment tells them something about their social standing in the society (Tyler \& Lind, 1992). Similarly, the threat of sanctions alters not only the cost-benefit implications of an action but also our understanding of the relevant social relationships. For example, through being forced to follow a course of action against our will we may come to see our relationship with an authority as unequal and conflictual, which in turn will make it difficult for the authority to subsequently appeal to a sense of duty to obey (Turner, 2005). Moreover, if attack behaviour serves to enact a group identity and understanding of the world, then sanctions will not necessarily counteract the motivation for it in the way that a simple cost-benefit account would suggest. For example, in the case of a terrorist group whose very raison d'être is rooted in the perceived illegitimacy of the status quo, sanctioning by the authorities would be entirely in line with the worldview from which their violence derives its meaning. Indeed, as Turner also points out, to be punished by an illegitimate authority could become a badge of honour, just as a promise of reward can be resented as an attempt to control through bribery. The point is that whether a reward or sanction serves to encourage or discourage a behaviour has as much to do with the social relationship within which they are administered as with any kind of inherent value. Moreover, to the extent that sanctions are felt by a wider group of people than those already engaged in conflict, there is the potential for escalation as is seen most clearly in studies of 'public order' policing (e.g., Reicher, 1996). 
If the authority imposing a political sanction is viewed as being aligned or partial to an outgroup, then attackers are unlikely to identify with these decision-makers and will claim that this institution does not serve their interests (Pehrson, Devaney, Blaylock, \& Bryan, 2017; Radburn, Stott, Bradford, \& Robinson, 2016). Despite the risk of a sanction, lack of identification is a basis for rejecting unfavourable decisions (Huo, Smith, Tyler, \& Lind, 1996). On the other hand, if the institutions are viewed by potential attackers as representative of a wider ingroup, then the picture is more optimistic. Because identification with an authority forms the basis for their legitimacy, it is more likely that even sanctions could be accepted so long as the authority represents a wider ingroup and is therefore legitimate. Thus, in settings where an authority is genuinely accepted as an 'honest broker' in managing competing intergroup interests, and thus able to secure the interests and loyalty of multiple parties by keeping the peace, then it does indeed have an important role to place in minimizing attack whether between individuals or groups. On the other hand, when the fate of the group is on the line and ingroup authorities act in a way that is seen as partisan, sanctioning can have devastating effects. Processes underpinning identification with authorities are dynamic and thus, even where an authority is initially viewed as part of an ingroup, sanctioning may well disrupt this (Radburn \& Stott, 2018).

Taking these insights into account, we would like to extend the implications of De Dreu and Gross by adding that policymakers wishing to discuss the effectiveness of political sanctioning in discouraging attacks should carefully assess the source or the institution of the sanctioning (whether it is understood by the targets of sanction to be representative of ingroup, outgroup or superordinate interests) and how the sanctioning itself would affect this. Ultimately, efforts to foster high levels of identification with the political authorities should be deployed to ensure that political sanctioning does not fail and even intensifies the desire to attack.

\section{References}

Adams, J. S. (1966). Inequity in social exchange. Advances in Experimental Social Psychology, 2, 267-299. https://doi.org/10.1016/S0065-2601(08)60108-2

Guimond, S., De Oliveira, P., Lalonde, K. N., Lalonde, R. N., Pratto, F., Sidanius, J., ... Zick, A. (2013). Diversity policy, social dominance, and intergroup relations: Predicting prejudice in changing social and political contexts. Journal of Personality and Social Psychology, 104, 941-958. https://doi.org/10.1037/a0032069

Huo, Y. J., Smith, H. J., Tyler, T. R., \& Lind, E. A. (1996). Identification and justice concerns: Is separatism the problem; is assimilation the answer? Psychological Science, 7, 40-45. https://doi.org/10.1111/j.1467-9280.1996.tb00664.x

Messick, D. M., \& Cook, K. S. (1983). Equity theory: Psychological and sociological perspectives. New York, NY: Praeger Publishers.

Pehrson, S., Devaney, L., Blaylock, D., \& Bryan, D. (2017). Beyond group engagement: Multiple pathways from encounters with the police to cooperation and compliance in Northern Ireland. PLOS ONE. https://doi.org/https://doi.org/10.1371/journal.pone.0184436

Radburn, M., \& Stott, C. (2018). The social psychological processes of "procedural justice": Concepts, critiques and opportunities. Criminology and Criminal Justice. https://doi.org/10.1177/1748895818780200

Radburn, M., Stott, C., Bradford, B., \& Robinson, M. (2016). When is policing fair? Groups, identity and judgements of the procedural justice of coercive crowd policing. Policing and Society. https://doi.org/10.1080/10439463.2016.1234470

Reicher, S. D. (1996). "The Battle of Westminster": Developing the social identity model of crowd behaviour in order to explain the initiation and development of collective conflict. European Journal of Social Psychology, 26, 115-134. https://doi.org/10.1002/(sici)10990992(199601)26:1<115::aid-ejsp740>3.3.co;2-q

Tankard, M. E., \& Paluck, E. L. (2016). Norm perception as a vehicle for social change. Social Issues and Policy Review, 10, 181-211.

Tyler, T. R. (2006). Why people obey the law (2nd ed.). New Haven, CT: Yale University Press.

Tyler, T. R., \& Lind, E. A. (1992). A relational model of authority in groups. In Advances in Experimental Social Psychology (Vol. 25) (pp. 115-182). New York, NY: Academic Press. https://doi.org/10.1016/S0065-2601(08)60283-X 